\title{
Contribution of Mass Elevation Effect to the Altitudinal Distribution of Global Treelines
}

\author{
ZHAO Fang1,2 (D http://orcid.org/oooo-ooo1-9225-104X; e-mail: zhaofang@lreis.ac.cn \\ ZHANG Bai-ping1,3* (D)http://orcid.org/oooo-0003-4298-9526; Me-mail: zhangbp@lreis.ac.cn \\ ZHANG Shuo', (D http://orcid.org/oooo-ooo1-7842-5875; e-mail: zhangshuo@lreis.ac.cn \\ QI Wen-wen ${ }^{1,2}$ iD http://orcid.org/oooo-0002-8439-4339; e-mail: qiww@lreis.ac.cn \\ HE Wen-hui ${ }^{1,2}$ (D) http://orcid.org/oooo-0002-9155-3393; e-mail: hewh@lreis.ac.cn \\ WANG Jing1,2 (i) http://orcid.org/oooo-0001-7205-1315; e-mail: wangj.13b@igsnrr.ac.cn

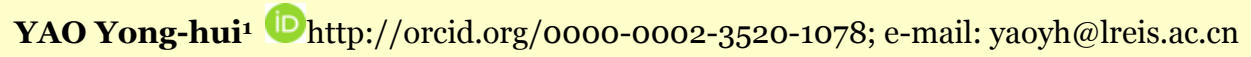 \\ 1 State Key Laboratory of Resource and Environment Information System, Institute of Geographic Sciences and Natural \\ Resources Research, Chinese Academy of Sciences, Beijing 100101, China \\ 2 University of Chinese Academy of Sciences, Beijing 100049, China \\ 3 Jiangsu Center for Collaborative Innovation in Geographical Information Resource Development and Application, \\ Nanjing 210023, China
}

Citation: Zhao F, Zhang BP, Zhang S, et al. (2015) Contribution of mass elevation effect to the altitudinal distribution of global treelines. Journal of Mountain Science 12(2). DOI: 10.1007/s11629-014-3223-x

(C) Science Press and Institute of Mountain Hazards and Environment, CAS and Springer-Verlag Berlin Heidelberg 2015

\begin{abstract}
Alpine treeline, as a prominent ecological boundary between forested mountain slopes and alpine meadow/shrub, is highly complex in altitudinal distribution and sensitive to warming climate. Great efforts have been made to explore their distribution patterns and ecological mechanisms that determine these patterns for more than 100 years, and quite a number of geographical and ecophysiological models have been developed to correlate treeline altitude with latitude or a latitude related temperature. However, on a global scale, all of these models have great difficulties to accurately predict treeline elevation due to the extreme diversity of treeline site conditions. One of the major reasons is that "mass elevation effect" (MEE) has not been quantified globally and related with global treeline elevations although it has been observed and its effect on treeline elevations in the Eurasian continent and Northern Hemisphere recognized. In this study, we collected and compiled a total of 594 treeline sites all over the world from literatures, and explored how MEE affects global
\end{abstract}

Received: 25 July 2014

Accepted: 4 February 2015 treeline elevation by developing a ternary linear regression model with intra-mountain base elevation (IMBE, as a proxy of MEE), latitude and continentality as independent variables. The results indicated that IMBE, latitude and continentality together could explain $92 \%$ of global treeline elevation variability, and that IMBE contributes the most (52.2\%), latitude the second (40\%) and continentality the least $(7.8 \%)$ to the altitudinal distribution of global treelines. In the Northern Hemisphere, the three factors' contributions amount to 50.4\%, 45.9\% and $3.7 \%$ respectively; in the south hemisphere, their contributions are $38.3 \%, 53 \%$, and $8.7 \%$, respectively. This indicates that MEE, virtually the heating effect of macro-landforms, is actually the most significant factor for the altitudinal distribution of treelines across the globe, and that latitude is relatively more significant for treeline elevation in the Southern Hemisphere probably due to fewer macro-landforms there.

Keywords: Alpine treeline; Intra-mountain base elevation; Multiple regression analysis; Geographical 
factor; Continentality; Contribution rate

\section{Introduction}

Alpine treeline is an ecological boundary between continuous montane forests to the extreme upper limit of the occurrence of tree species in high mountains. It has been studied for more than 100 years in many disciplines, including geography, biogeography, ecology, climatology, etc. Treeline position has been considered a crucial ecological marker for the lower limit of alpine belts and also a sensitive indicator of climate warming (Troll 1973; Kullman 2007; Rössler et al. 2008).

Treeline elevation has been often associated with latitude or latitude-related temperature, and a number of treeline elevation-latitude models have been developed to determine treeline elevation at regional and global scales (Malyshev 1993; Cogbill et al. 1991; Fang 1995; Körner 1998). However, regional models are only effective regionally and cannot be applied to global scale. For example, according to the Malyshev (1993)'s Ural model, treelines near $30^{\circ} \mathrm{N}$ should be at $2950 \mathrm{~m}$, but they are actually at $4800-4900 \mathrm{~m}$ in the southeast Tibetan Plateau (Schickhoff 2005; Miehe et al. 2007). Körner (1998)'s global model roughly outlines the latitudinal pattern of treeline elevations at a global scale, but cannot accurately predict treeline elevation, because treeline elevation does not have strict correlation with latitude globally. As a matter of fact, treeline elevation can vary greatly at the same latitude, for example, it can rise from $3500 \mathrm{~m}$ (Zhong 1983) on the eastern slope of the Gongga Mountains in the eastern periphery of the Tibetan Plateau to $4900 \mathrm{~m}$ (Miehe et al. 2007) in Baxoi County in the inner Tibetan Plateau at $30^{\circ} \mathrm{N}$ with a difference of as large as $1400 \mathrm{~m}$. There is no doubt that some environmental factors unrelated to latitude must have reshaped the altitudinal distribution of global treelines (Körner 1998).

Eco-physiologically, treeline formation and maintenance has been directly related with some isotherms, involving the warmest month air temperature of $10^{\circ} \mathrm{C}$ (Daubenmire 1954; Grace 1977; Ohsawa 1990), annual biotemperature of $3^{\circ} \mathrm{C}$ (Holdridge 1947, 1967), warmth index (WI) of $15^{\circ} \mathrm{C}$-month (Kira 1945; Ohsawa 1990; Fang et al.
1996), seasonal mean ground temperature of $6.7^{\circ} \mathrm{C} \pm 0.8^{\circ} \mathrm{C}$ (Körner $1998 \mathrm{~b}$; Körner et al. 2004), etc. But it has been found that treeline elevation varies greatly in mountains at similar latitudes (e.g., by $1400 \mathrm{~m}$ as mentioned above), implying a great difference in the altitudinal positions of these isotherms. What factors on earth bring about such tremendous difference?

Treeline elevations have been found to ascend from polar to tropical regions, from island to continental inland, and from the periphery to central parts of large mountain massifs (Holtmeier 2009). Many factors interplay to give rise to these patterns of distribution, including zonal factors (latitude, aridity or precipitation), regional factors (macro-landform, relief) and local factors, e.g., slope and aspect, soil, human intervenes, ocean currents, species competition, beetle infestations, invasive pathogens, herbivores, etc. (Holtmeier 2005). Mean annual temperature and seasonal thermal amplitude were ever used to model global altitudinal distribution of treelines (Jobbagy et al. 2000). The two factors, to a great extent, can be reflected with latitude and continentality, respectively. The large thermo-dynamic effects of massive mountains have long been overlooked. At continental and hemispheric scales, it has recently been shown that latitude, continentality and mass elevation effect (MEE) together play a major role in the altitudinal distribution of treelines (Zhao et al. 2014; Han et al. 2012). It means that these three factors, especially MEE, must be taken into account if a global high-accuracy treeline model is to be developed.

The question we now face is that MEE has not been adequately quantified globally. We consider that looking for a proxy for MEE may be a feasible method to quantify MEE at present. The top height or average height of mountains seems to be such a proxy, but treelines may not be very high in some high mountains. For example, the absolute height of Mt. Kilimanjaro is as high as $5895 \mathrm{~m}$ above sea level and it is even close to the equator, but the treeline is at about only $3500 \mathrm{~m}$ (Hemp 2006), about 1100 1400 $\mathrm{m}$ lower than in the interior Tibetan Plateau (Schickhoff 2005). The reason may be that it's a volcanic cone without intra-mountain plateaus or basins, and that mountain slopes are all completely exposed to the free air, so the temperature difference between the mountain 


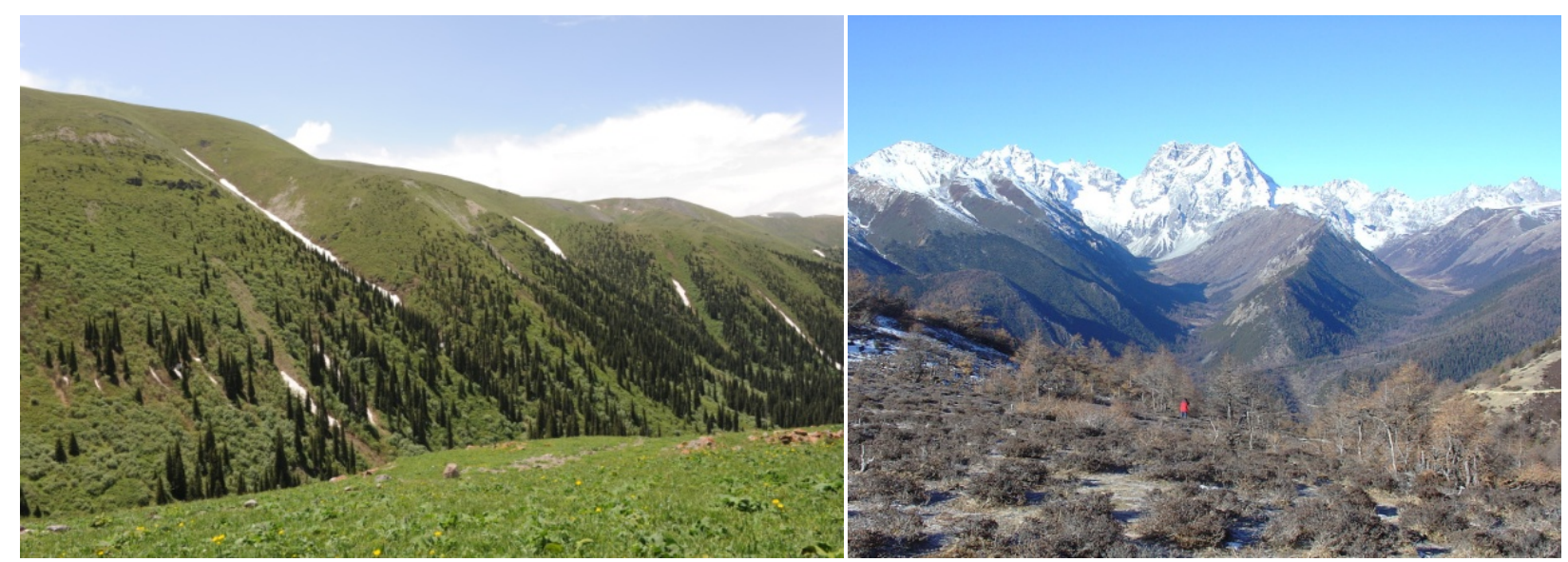

Figure 1 Two treeline examples at 2800-3000 $\mathrm{m}$ in the western Tianshan Mts. of Xinjiang (left) and at $4300-4400 \mathrm{~m}$ in the Baima Snow Mts. of Yunnan (right) in China.

surface and the free air at the same altitude may be very small. If the mountains are broad and there exist intra-mountain plateaus and basins, such as the interior Tibetan Plateau, treelines are much higher even though they are farther from the equator. In other words, the higher the inner plateaus and basins are, the higher the treeline elevations (Figure 1). Based on this consideration, we consider that IMBE (intra-mountain base elevation) can serve as the proxy of MEE. In this study, we intend to evaluate the significance of MEE for the altitudinal distribution of global treelines by analyzing the contribution of IMBE to global treeline elevations; and to compare the difference in the contribution of MEE between the Northern Hemisphere and Southern Hemisphere.

\section{Material and Methods}

\subsection{Treeline data set}

Treeline was defined as ecotone between continuous forest (timberline) and the highest patches of tree species (tree species line) composed of trees of at least $3 \mathrm{~m}$ height (Körner et al. 2004). Based on this definition, we collected a data set of treeline sites involving their elevation and geographic coordinates (latitude, longitude) from published literatures. If authors did not explicitly state tree height, but only described ranges of a treeline ecotone, took the middle position of the ecotone as treeline elevation. Treeline data sites were discarded if their elevations, according to literature descriptions, have been depressed by human disturbance, fire, natural disasters, etc. Moreover, the vertical distance between treeline and mountain summit should be at least 200m so as to minimize the very local climatic effect near the summit on treeline elevation.

Following these criteria, we selected and compiled a total of 594 treeline sites covering almost all the mountains and plateaus globally (Figure 2), from about 130 publications. It is noticeable that most of the treeline sites are in the Northern Hemisphere and only a few in the Southern Hemisphere. This is because there are much more high mountains in the Northern Hemisphere than in the Southern.

\subsection{Data set for intra-mountain base elevation}

Mountain base elevation (MBE) was commonly defined as the altitude of the basal zone in the previous studies on mountain altitudinal belts (Liu 1981; Zhang et al. 1988). It was generally taken as the average elevation of foothills in isolated mountains in the plain and hilly areas without intra-montane basins or valleys, e.g., Mt. Kilimanjaro (Hemp 2006). For oceanic islands such as Tenerife in the insular Spain, MBE is zero. However, for the immense and towering Tibetan Plateau covering an area of nearly 2.5 million $\mathrm{km}^{2}$, there are many local bases, not only in the peripheral plains, but also in the interior basins and valleys (Zhang 1978; Hou 1982). The average height of these basins and valleys was defined as 


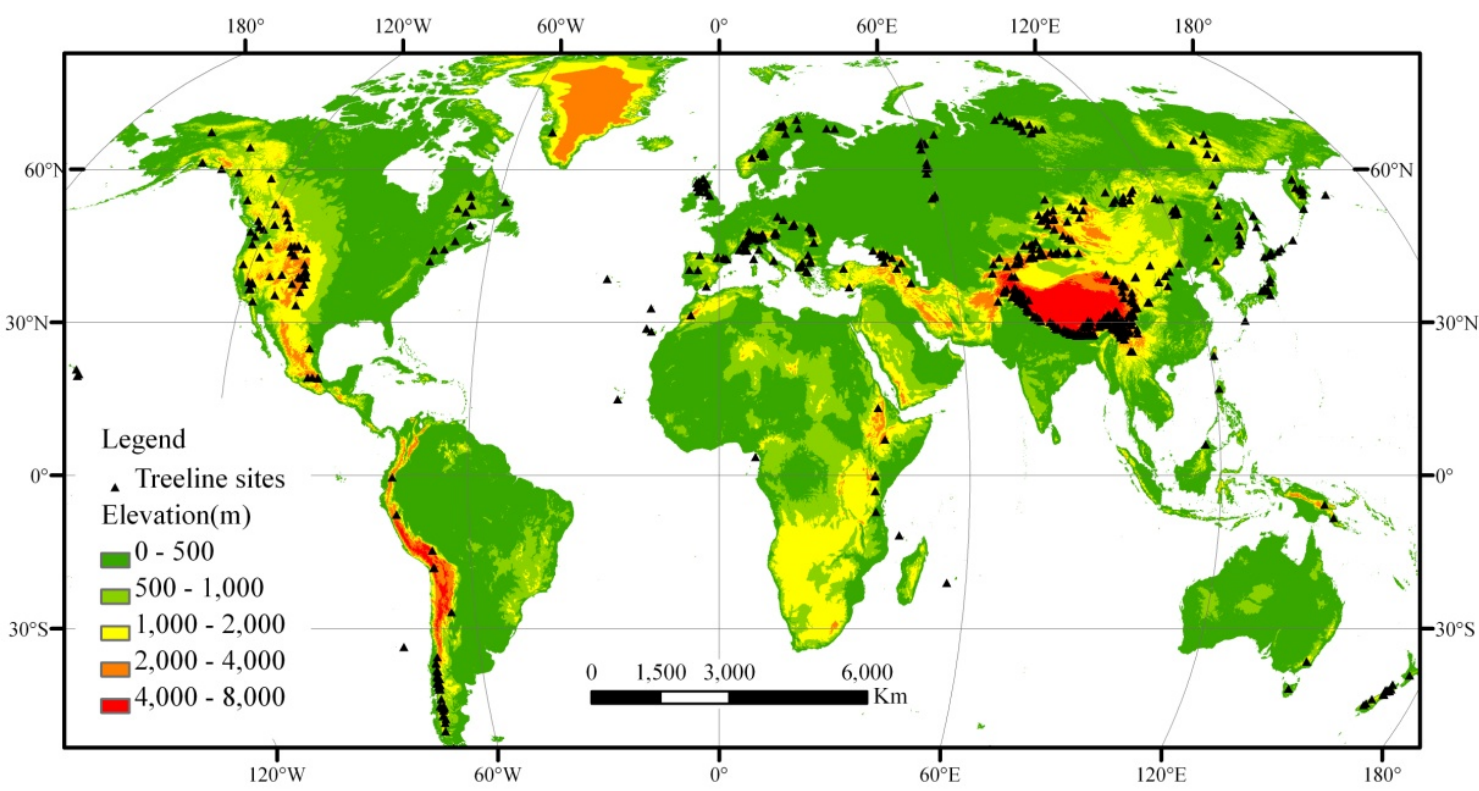

Figure 2 Distribution of 594 global treeline data sites used in this study.

intra-mountain base elevation (IMBE). Usually, IMBE becomes higher and higher from the peripheral toward the inner plateau, e.g., it is about $3700 \mathrm{~m}$ in Lhasa, $4300-4500 \mathrm{~m}$ in the most parts of the plateau, and $4500-4800 \mathrm{~m}$ in its northwest (Zhang et al. 1988). For the isolated mountains, such as Kilimanjaro, due to the lack of intramontane basins or valleys, IMBE is actually equivalent to MBE. According to these definitions we manually extracted IMBEs for the 594 treeline data sites worldwide based on the topographical data from SRTM $90 \mathrm{~m}$ Digital Elevation Data (http://srtm.csi.cgiar.org/). The detailed method for calculating IMBE is based on Zhang et al. (2012).

\subsection{Climatic variables}

Climatic data for monthly mean temperatures at treeline positions were extracted from WorldClim database (Hijmans et al. 2005), which provided interpolated climate surfaces at a spatial resolution of 30 arcs (equivalent to $860 \mathrm{~m}$ ) for 1950-2000 and has been widely used in several macro-ecological studies (Szabo et al. 2009; Casalegno et al. 2010; Kessler et al. 2011). We calculated continentality for each treeline site based on the following Gorczynski's formulas (1922).

Northern Hemisphere:

$$
K=1.7 \times \frac{A}{\operatorname{Sin} \phi}-20.4
$$

Southern Hemisphere:

$$
K=1.6 \times \frac{A}{\operatorname{Sin} \phi}-14.4
$$

where $K$ is continentality, $\Phi$ is latitude (to avoid the denominator to be zero, take $\Phi$ as 10 when $|\Phi|<10$ ), and $A$ is the difference of mean temperatures of the warmest and the coldest months.

\subsection{Data analyses}

We performed a multiple regression analysis with treeline elevation as the dependent variable, and the three variables (latitude, continentality and IMBE) as independent variables. The multiple regression model is as follows:

$$
\mathrm{TL}(m)=a \times L a t+b \times K+c \times I M B E+d
$$

where TL is treeline elevation, Lat latitude, IMBE the proxy of MEE, $\mathrm{K}$ continentality; $\mathrm{a}, \mathrm{b}$ and $\mathrm{c}$ are coefficients of independent variables, $d$ is constant term.

Based on this model we calculated the predicted values of treeline elevations and graphed the relationship between predicted and actual treeline elevations with $95 \%$ confidence interval globally. Kruskal-Wallis (K-W) test was carried out to test the significance of the independent variables 
and the model. A collinearity test based on variance inflation factor (VIF) and tolerance was also conducted to examine the multicollinearity among the independent variables. Supposing that the combined effects of the three independent variables to the altitudinal distribution of treelines is $100 \%$, their respective contribution rates can be figured out based on their standardized coefficients.

\section{Results}

\subsection{Global treeline elevation model}

As shown in Figure 3, treeline elevation displays an obvious tendency to lowering with increased latitude from latitude $30^{\circ} \mathrm{N}$ to latitude $70^{\circ} \mathrm{N}$ and from latitude $20^{\circ} \mathrm{S}$ to latitude $60^{\circ} \mathrm{S}$; while from $30^{\circ} \mathrm{N}$ and $20^{\circ} \mathrm{S}$ to the equator, there is a slight decrease in treeline elevation (Figure 2). The highest treelines do not occur in the equatorial regions but in the subtropics at $30^{\circ} \mathrm{N}$ and $20^{\circ} \mathrm{S}$.

$\mathrm{K}-\mathrm{W}$ non-parametric test shows that the differences among latitude, continentality, and IMBE are significant with $\mathrm{P}<0.01$. Collinearity statistics shows that there is no multicollinearity among the three independent variables with VIF $<$ 5 and tolerance $>0.2$. The multiple regression model developed globally explains $92 \%$ of the altitudinal variation of treelines with $\mathrm{R}^{2}$ as high as 0.92 . Unstandardized Coefficients and 95\% confidence interval for parameter estimates describe the relationship between treeline elevation and latitude, continentality and IMBE. It reveals that treeline elevation drops for approximately $47 \mathrm{~m}$ per degree increase of latitude when other parameters keep unchanged; while it is elevated by $80 \mathrm{~m}$ for $100 \mathrm{~m}$ increase in IMBE and by $56 \mathrm{~m}$ for 10 unit increase of continentality (Table 1). The linear regression line and $95 \%$ confidence interval shown in Figure 4 reflects the close relationship between the actual and predicted treeline elevation. Standard regression coefficients indicate that the contributing rate is $52.2 \%$ by IMBE, $40 \%$ by latitude, and only $7.8 \%$ by continentality. This means that IMBE serves as the most significant factor for global treeline elevation distribution.

\subsection{Treeline elevation model for the Northern Hemisphere}

The model developed for the Northern Hemisphere explains $93 \%$ of the altitudinal variation of treelines. $\mathrm{K}-\mathrm{W}$ test and collinearity statistics all have the same result as for the global

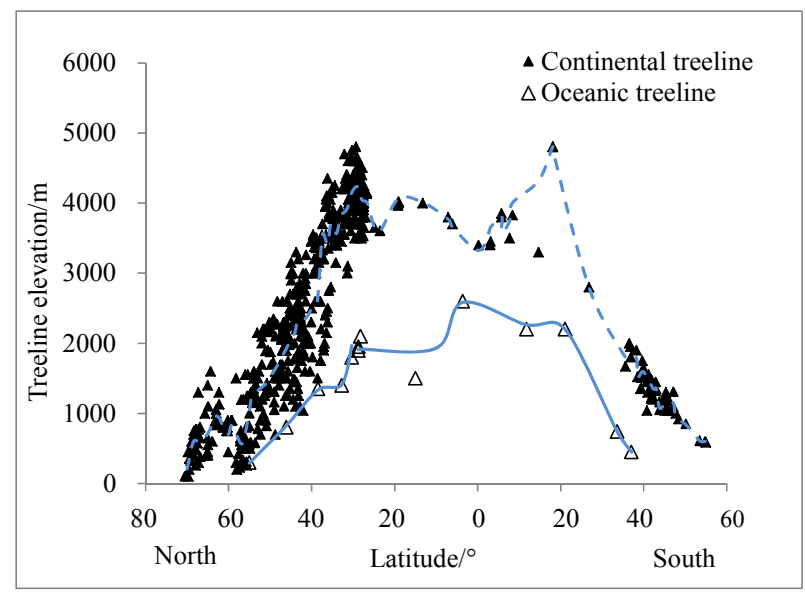

Figure 3 Latitudinal pattern of global treeline elevation distribution (Data from published literatures).

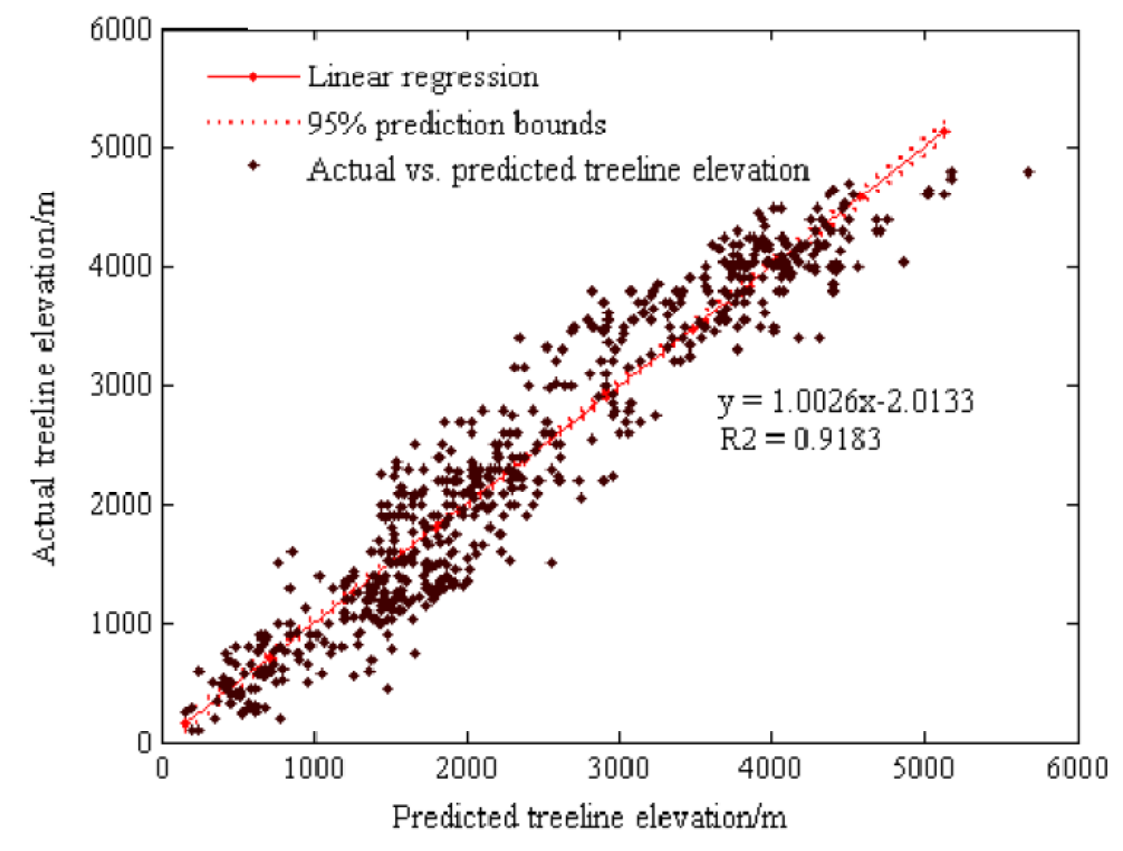

Figure 4 Linear-regressed trend line with 95\% predicted interval showing the relationship between actual and predicted treeline elevation of global treelines. 
model. Treeline elevation drops by approximately $53 \mathrm{~m}$ per degree increase of latitude when other parameters keep unchanged in the Northern Hemisphere; while treeline is elevated by about $74 \mathrm{~m}$ for $100 \mathrm{~m}$ increase in IMBE and by $27 \mathrm{~m}$ for 10 unit increase in continentality (Table 1). The standard regression coefficients reveal that IMBE still has the highest contribution rate of as high as $50.4 \%$ with latitude the second (45.9\%) and continentality the least (3.7\%).

\subsection{Treeline elevation model for the Southern Hemisphere}

The multiple regression model explains the altitudinal distribution of treelines almost perfectly in the Southern Hemisphere, with $\mathrm{R}^{2}$ as high as 0.94. K-W test and collinearity statistics all have the same results as for the global model. Treeline elevation drops by approximately $44 \mathrm{~m}$ per degree increase of latitude, and increases by $61 \mathrm{~m}$ for $100 \mathrm{~m}$ increase of IMBE and by $19 \mathrm{~m}$ for 10 unit increase of continentality when other parameters keep unchanged (Table 1). But, unlike the case in the Northern Hemisphere, latitude becomes the leading factor with a contribution rate of $53 \%$, IMBE the second (38.3\%) and continentality the least (8.7\%).

\subsection{Residual analysis}

To analyze the prediction accuracy of the multiple regression models, we calculated the residual between the predicted and actual values of the treeline elevations. According to the results of residual analysis (Figure 5), most of the standardized residuals are distributed around zero in the three cases, and the error term agrees with a normal assumption, which further confirms the validity of the multiple regression models in this study.

\section{Discussion and Conclusions}

Our study confirms that the altitudinal distributions of treelines at global and hemispherical scales are mainly controlled by the combined effect of IMBE, latitude and continentality. With the three factors, we are able to explain over $90 \%$ of the global and hemispherical variability of treeline elevation. That is a great step forward from the result by Jobbagy and Jackson (2000). In their model, almost no high treelines (above 3500m) are included and only $79 \%$ of the global variability of treeline elevation is explained. Our model, by contrast, has higher capability of explanation and quite satisfactorily deals with these high treelines. According to our model, the occurrence of high treelines at similar latitudes is closely related to MEE (reflected by IMBE) and continentality, which is very consistent with Schickhoff's (2005) conclusion.

\begin{tabular}{|c|c|c|c|c|c|c|c|c|c|}
\hline Model & & K-W test $H / d f /$ Sig. & $\mathbf{R}^{2}$ & Ci & C2 & CR(\%) & P-value & CT/ VIF & $\begin{array}{l}95 \% \\
\text { confidence } \\
\text { interval }\end{array}$ \\
\hline \multirow[t]{4}{*}{ Globe } & Constant & & & 3223 & & & $<0.01$ & & $(30603387)$ \\
\hline & Latitude & & & -47.1 & -0.46 & 40 & $<0.01$ & $0.54 / 1.86$ & $(-50.33-43.88)$ \\
\hline & Continentality & $939 / 2 /<0.01$ & 0.92 & 5.63 & 0.09 & 7.8 & $<0.01$ & $0.87 / 1.15$ & $(47.27)$ \\
\hline & IMBE & & & 0.80 & 0.60 & 52.2 & $<0.01$ & $0.55 / 1.81$ & $(0.760 .85)$ \\
\hline \multirow{4}{*}{$\begin{array}{l}\text { Northern } \\
\text { Hemisphere }\end{array}$} & Constant & & & 3712 & & & $<0.01$ & & (3529 3895) \\
\hline & Latitude & & & -52.78 & -0.50 & $45 \cdot 9$ & $<0.01$ & $0.48 / 2.08$ & $(-56.19-49.36)$ \\
\hline & Continentality & $831 / 2 /<0.01$ & 0.93 & 2.66 & 0.04 & 3.7 & $<0.01$ & $0.93 / 1.08$ & $(1.044 .29)$ \\
\hline & IMBE & & & 0.74 & 0.55 & 50.4 & $<0.01$ & $0.50 / 2.01$ & (o.69 0.78$)$ \\
\hline \multirow{4}{*}{$\begin{array}{l}\text { Southern } \\
\text { Hemisphere }\end{array}$} & Constant & & & 2713 & & & $<0.01$ & & $(24173010)$ \\
\hline & Latitude & & & -44.28 & -0.61 & 53 & $<0.01$ & $0.66 / 1.52$ & $(-49.53-39.03)$ \\
\hline & Continentality & $120 / 2 /<0.01$ & 0.94 & 19.33 & 0.10 & 8.7 & $<0.01$ & $0.79 / 1.27$ & $(6.4832 .19)$ \\
\hline & IMBE & & & 0.61 & 0.44 & 38.3 & $<0.01$ & $0.68 / 1.46$ & (0.51 0.71$)$ \\
\hline
\end{tabular}

Notes: $\mathrm{CR}=$ Contribution rate; $\mathrm{CT} / \mathrm{VIF}=$ Collinearity tolerance /variance inflation factor; $\mathrm{C} 1$ and $\mathrm{C} 2$ refer to Unstandardized coefficients and Standardized coefficients, respectively; IMBE means intra-mountain base elevation. 

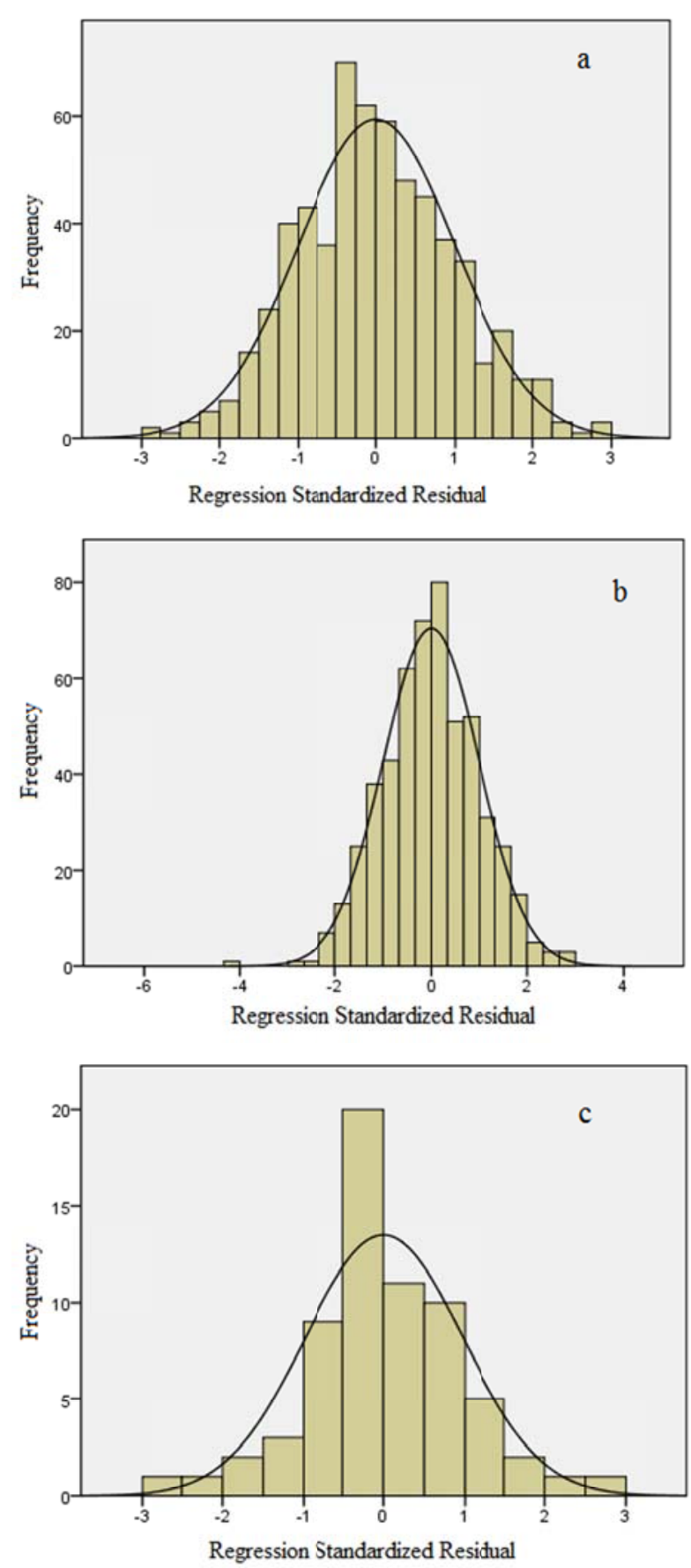

Figure 5 Standardized residual of the altitudinal distribution of treelines for the globe (a), the Northern Hemisphere (b) and the Southern Hemisphere (c).

Of the three variables we considered (IMBE, latitude and continentality), IMBE contributes most to the altitudinal variation of global treelines meaning that MEE is the most significant factor in modeling global treeline elevation variability. This is in line with our previous studies on the altitudinal distribution of treelines in the northern hemispherical (Zhao et al. 2014) and southeastern hemispherical (Han et al. 2012). However, it is surprisingly different from what has been expected-temperatures associated with Latitude and continentality should be the major factor for treeline elevation distribution (Wardle 1974; Cogbill et al. 1991; Malyshev 1993; Jobbagy et al. 2000). We consider that MEE has been underestimated as a key factor influencing global treeline distribution patterns. In other words, MEE is a key factor in developing a high-accuracy model for the altitudinal distribution of treelines at a global scale.

The contribution of IMBE to treeline elevation varies greatly between the two hemispheres: 50.4\% in the Northern Hemisphere and $38.3 \%$ in the southern. This is reasonable, for a number of immense plateaus and mountain ranges are located in the Northern Hemisphere. In the Southern Hemisphere, however, only the Andes range is massive, and it runs roughly north-south coinciding with the latitudinal differentiation of temperature.

The mechanism of MEE has much to do with the heating effect of extensive mountain massifs at the global scale, as global treelines are mainly controlled by temperature (Daubenmire 1954; Jobbagy et al. 2000). High mountain massifs can improve the thermal conditions through the sensible heat transfer associated with elevated heating surface directly (Barry 2008; Holtmeier 2009) and latent heat caused by convective activity and orographic precipitation indirectly (Yeh et al. 1974; Rao et al. 1989). As a result, temperature is higher in the interior of mountain chains or plateaus with high local base elevation than in the free atmosphere above the peripheral low land. For example, monthly mean temperature in the interior Tibetan Plateau is $3.58^{\circ} \mathrm{C}-6.63^{\circ} \mathrm{C}$ higher than in the eastern Sichuan Basin at $4500 \mathrm{~m}$, according to Yao et al. (2014), which causes treelines to rise by about $500-1000 \mathrm{~m}$ in the inner main plateau than in the eastern border areas. At regional and local scales, MEE is also related with continentality (Whitmore 1984; Schickhoff 2005; Holtmeier 2009), species competition (VanSteenis 1961; Hall 1984), availability of soil mineral nutrients (Grubb 1971), and even human disturbances and geomorphologic constraints (Leonelli et al. 2009). 
Although our treeline elevation distribution models are of high accuracy, there are still some outliers mainly on oceanic islands. Actual treeline elevations are obviously lower than predicted. The depression of actual treelines on oceanic island mountains may be attributed to many local factors, e.g. temperature inversions by the dry trade-wind belt, immature volcanic soils and other factors (Leuschner 1996), which should be considered in future research of local treeline distribution. Anyhow, the multiple regression model taking latitude, continentality, and IMBE as independent variable is quite robust at global and hemispheric scales.

Besides uplifting treeline, MEE can also put upward snowline (Han et al. 2011), affect continentality (Holtmeier 2009), enrich the biomass of invertebrate (Leakey et al. 1987), reduce the susceptibility of resident species to extrinsic

\section{References}

Barry RG (2008) Mountain Weather and Climate. Cambridge University Press, New York, USA.

Bussmann RW (2006) Vegetation zonation and nomenclature of African Mountains - An overview. Lyonia 11(1): 41-66.

Casalegno S, Amatulli G, Camia A, et al. (2010) Vulnerability of Pinus cembra L. in the Alps and the Carpathian mountains under present and future climates. Forest Ecology and Management 259: 750-761. DOI: 10.1016/j.foreco.2009.10. o01.

Cogbill CV, White PS (1991) The latitude-elevation relationship for spruce-fir forest and treeline along the Appalachian mountain chain. Vegetatio 94: 153-175. DOI: 10.1007/BFoo032629.

Cronk QCB (1997) Islands: stability, diversity, conservation. Biodiversity and Conservation 6: 477-493.

Daubenmire R (1954) Alpine timberlines in the Americas and their interpretation. Butler University Botanical Studies 11: 119-135.

Ellenberg H (1988) Vegetation ecology of Central Europe. Cambridge University Press, New York, USA.

Fang JY (1995) Three-dimension distribution of forest zones in East Asia. Acta Geographica Sinica 50(2): 160-167. (In Chinese)

Fang JY, Oshawa M, Kira T (1996) Vertical vegetation zones along 30'N latitude in humid East Asia. Vegetatio 126: 135149. DOI: $10.1007 /$ BFooo456oo.

Flenley J (2007) Ultraviolet insolation and the tropical rainforest: altitudinal variations, Quaternary and recent change, extinctions, and biodiversity. In: Tropical Rainforest Responses to Climatic Change. Praxis, Chichester, UK.

Gorczynski L (1922) The calculation of the degree of continentality. Monthly Weather Review 50(7): 369-370. DOI: 10.1175/1520-0493(1922)50<370b:TCOTDO>2.0.CO;2

Grace J (1977) Plant Response to Wind. Academic Press, London, UK

Grubb JP (1971) Interpretation of Massenerhebung Effect on Tropical Mountains. Nature 1971(229): 44-45. DOI: $10.1038 / 229044 a 0$ disturbance, and even improve the stability of ecosystems (Cronk 1997). So its quantification can be expected to have a much wider application. Neverthless, using IMBE to represent MEE is an expedient measure at the moment. In future study, we will take into account mutiple factors, e.g. mountain surface properties, mean altitude, mountain structures, etc. to realize its direct and complete quantification.

\section{Acknowledgment}

The research is supported by the National Natural Science Foundation of China (Grant Nos. 41030528 and No. 40971064). We are very grateful to Dr. Han, F. and Tan, J. for their help with treeline elevation data.

Hall JB (1984) Juniperus excelsa in Africa: A Biogeographical Study of an Afromontane Tree. Journal of Biogeography 11(1): 47-61. DOI: $10.2307 / 2844775$

Han F, Zhang BP, Yao YH, et al (2011) Mass elevation effect and its contribution to the altitude of snowline in the Tibetan Plateau and surrounding areas. Arctic, Antarctic, and Alpine Research 43(2): 207-212. DOI: 10.1657/1938-4246-43.2.207

Hemp A (2006) Continuum or zonation? Altitudinal gradients in the forest vegetation of Mt. Kilimanjaro. Plant Ecology 184(1): 27-42. DOI: $10.1007 /$ s11258-005-9049-4

Hijmans RJ, Cameron SE, Parra JL, et al. (2005) Very high resolution interpolated climate surfaces for global land areas. International Journal Of Climatology 25: 1965-1978. DOI: 10.1002/joc. 1276

Holdridge LR (1947) Determination of world plant formations from simple climatic data. Science 105(2727): 367-368. DOI: 10.1126/science.105.2727.367

Holdridge LR (1967) Life zone ecology, Rev. edn. Tropical Science Center, San Jose, Costa Rica.

Holtmeier FK (2009) Mountain Timberlines Ecology, Patchiness, and Dynamics, 2nd edition. Springer Verlag, New York, USA.

Holtmeier FK, Broll G (2005) Sensitivity and response of Northern Hemisphere altitudinal and polar treelines to environmental change at landscape and local scales. Global Ecology and Biogeography 14(5): 395-410. DOI: 10.1111/ j.1466-822x.2005.00168.x

Hou X (1982) Vegetational geography and chemical components of dominant plants in China. Science Press, Beijing, China. (In Chinese)

Jobbagy EG, Jackson RB (2000) Global controls of forest line elevation in the northern and Southern Hemispheres. Global Ecology and Biogeography 9(3): 253-268. DOI: 10.1046/ j.1365-2699.2000.00162.x

Körner C (1998) A re-assessment of high elevation treeline positions and their explanation. Oecologia 115(4): 445-459.

Körner C, Paulsen J (2004) A world-wide study of high altitude treeline temperatures. Journal of Biogeography 31(5): 713-732. 
DOI: $10.1111 / \mathrm{j} .1365-2699.2003 .01043 . x$

Körner C, Riedl S (2012) Alpine Treelines: Functional Ecology of the Global High Elevation Tree Limits. Springer, Basel, Switzerland. DOI: 10.1007/978-3-0348-0396-0

Kessler M, Kluge J, Hemp A, et al. (2011) A global comparative analysis of elevational species richness patterns of ferns. Global Ecology and Biogeography 20: 868-880. DOI: j.14668238.2011.00653.x

Kira T (1945) A new classification of climate in eastern asia as the basis for agricultural geography. Horticultural institute, Kyoto University, Kyoto, Japan.

Kullman L (2007) Tree line population monitoring of Pinus sylvestris in the Swedish Scandes, 1973-2005: implications for tree line theory and climate change ecology. Journal of Ecology 95: 41-52. DOI: 10.1111/j.1365-2745.2006.01190.x

Leakey RJG, Proctor J (1987) Invertebrates in the litter and soil at a range of altitudes on Gunung Silam, a small ultrabasic mountain in Sabah. Journal of Tropical Ecology 3: 119-129. DOI: $10.1017 /$ So26646740000184X

Leonelli G, Pelfini M, Morra di Cella U (2009) Detecting climatic treelines in the Italian Alps: the influence of geomorphological factors and human impacts. Physical Geography 3O(4): 338-352. DOI: 10.2747/0272-3646.30. 4.338

Leuschner C (1996) Timberline and alpine vegetation on the tropical and warm-temperate oceanic islands of the world: Elevation, structure and floristics. Vegetatio 123(2): 193-206. DOI: $10.1007 /$ BFo0118271

Liu $H$ (1981) The vertical zonation of mountain vegetation in China. Acta Geographica Sinica 36: 257-279. (In Chinese)

Malyshev L (1993) Levels of the upper forest boundary in Northern Asia. Vegetatio 109(2): 175-186. DOI: 10.1007/ BFoo0 44749

Miehe G, Miehe S, Vogel J, et al. (2007) Highest treeline in the Northern Hemisphere found in southern Tibet. Mountain Research and Development 27(2): 169-173. DOI: 10.1659/ mrd.o792

Ohsawa M (1990) An interpretation of latitudinal patterns of forest limits in South and East Asian mountains. Journal of Ecology 78(2): 326-339. DOI: 10.2307/2261115

Price LW (1978) Mountains of the pacific northwest, U.S.A.: a study in contrasts. Arctic and Alpine Research 10(2): 465-478.
DOI: $10.2307 / 1550781$

Rössler O, Bräuning A, Löffler J (2008) Dynamics and driving forces of treeline fluctuation and regeneration in central Norway during the past decades. Erdkunde 62: 117-128. DOI: 10.3112/erdkunde.2008.02.02

Rao GV, Erdogan S (1989) The atmospheric heat source over the Bolivian plateau for a mean January. Boundary-layer Meteorology 46(1): 13-33. DOI: 10.1007/BFoo118444

Schickhoff U (2005) The upper timberline in the Himalayas, Hindu Kush and Karakorum: a review of geographical and ecological aspects. In: mountain ecosystems. Springer Berlin/Heidelberg, German. DOI: 10.1007/b138976

Szabo ND, Algar AC, Kerr JT (2009) Reconciling topographic and climatic effects on widespread and range-restricted species richness. Global Ecology and Biogeography 18: 735744. DOI: $10.1111 / \mathrm{j} .1466-8238.2009 .00479 . x$

Troll C (1973) The upper timberlines in different climatic zones. Arctic and Alpine Research 5(3): A3-A18.

Vansteenis GJ (1961) An attempt towards an explanation of the effect of mountain mass elevation. Proceedings of the Royal Academy of Science of the Netherlands 64: 435-442.

Wardle P (1974) Alpine timberlines. In: Arctic and Alpine Environments. Methuen, London, UK.

Whitmore TC (1984) A vegetation map of Malesia at the scale of 1:5 million. Journal of Biogeography 11: 461-471. DOI: $10.2307 / 2844792$

Yao Y, Zhang BP (2014) The mass elevation effect of the Tibetan Plateau and its implications for Alpine treelines. International Journal of Climatology (accepted). DOI: 10.1002/joc.4123

Yeh TC, Chang CC (1974) Preliminary experimental simulation on heating effect of Tibetan Plateau on general circulation over eastern Asia in summer. Scientia Sinica 17(3): 397-420.

Zhang S, Yao YH, Pang Y, et al. (2012) Mountain basal elevation extraction in the Taiwan island. Journal of Geo-infomation Science 14: 562-568. (In Chinese)

Zhang, X (1978) The plateau zonality of vegetation in Xizang. Acta Botanica Sinica 6(2): 140-149. (In chinese)

Zhao F, Zhang BP, Pang Y, et al. (2014) A study of the contribution of mass elevation effect to the altitudinal distribution of timberline in the Northern Hemisphere. Journal of Geographical Sciences 24(2): 226-236. DOI: 10.1007/s11442-014-1084-4 